\title{
Corrigendum
}

\section{Corrigendum to "Effect of Intervention in Subjects with High Risk of Diabetes Mellitus in Pakistan"}

\author{
Muhammad Zafar Iqbal Hydrie, ${ }^{1,2}$ Abdul Basit, ${ }^{2}$ A. Samad Shera, ${ }^{3}$ and Akhtar Hussain ${ }^{1}$ \\ ${ }^{1}$ Section of International Community Health, Department of Community Medicine, Institute of Health and Society, \\ Faculty of Medicine, University of Oslo, P.O. Box 1130, Blindern, Oslo, Norway \\ ${ }^{2}$ Department of Medicine, Baqai Institute of Diabetology and Endocrinology, Baqai Medical University, \\ Plot No. 1-2, II-B, Block 2, Nazimabad, Karachi 74600, Pakistan \\ ${ }^{3}$ WHO Collaborating Centre, Diabetic Association of Pakistan, 5-E/3, Nazimabad, Karachi 74600, Pakistan
}

Correspondence should be addressed to Muhammad Zafar Iqbal Hydrie; zafarhydrie@gmail.com

Received 8 September 2015; Accepted 7 October 2015

Copyright (C) 2015 Muhammad Zafar Iqbal Hydrie et al. This is an open access article distributed under the Creative Commons Attribution License, which permits unrestricted use, distribution, and reproduction in any medium, provided the original work is properly cited.

With regard to the paper titled "Effect of Intervention in Subjects with High Risk of Diabetes Mellitus in Pakistan" by Hydrie et al. [1], it was stated that the protocol was approved by the Norwegian Research Council. But the statement was made by mistake.

All the subjects were from Pakistan and the project was approved by the appropriate Ethics Committee of Baqai Medical University (Baqai Institute of Diabetology and Endocrinology). All participants provided informed consent prior to the collection of any data and the project was conducted in accordance with the Declaration of Helsinki.

\section{References}

[1] M. Z. I. Hydrie, A. Basit, A. S. Shera, and A. Hussain, "Effect of intervention in subjects with high risk of diabetes mellitus in Pakistan," Journal of Nutrition and Metabolism, vol. 2012, Article ID 867604, 7 pages, 2012. 


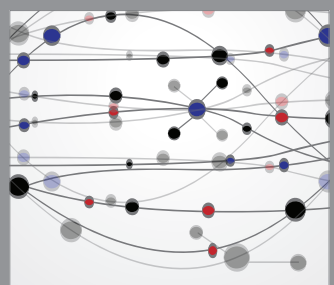

The Scientific World Journal
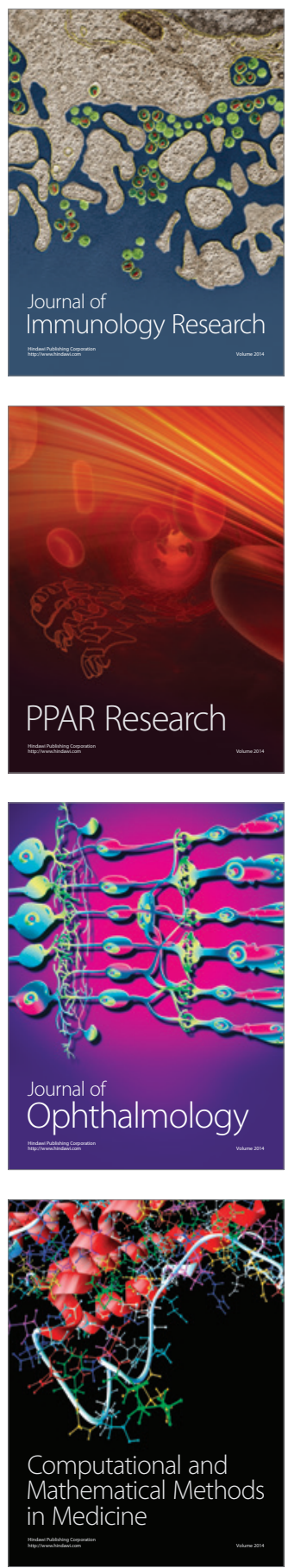

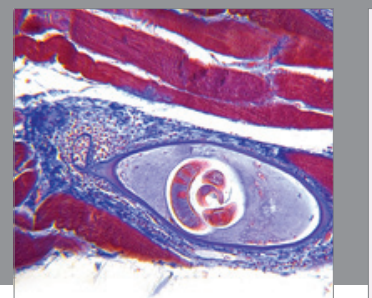

Gastroenterology

Research and Practice
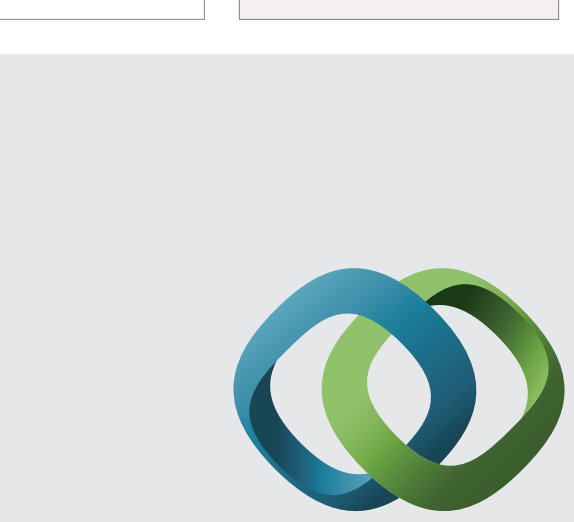

\section{Hindawi}

Submit your manuscripts at

http://www.hindawi.com
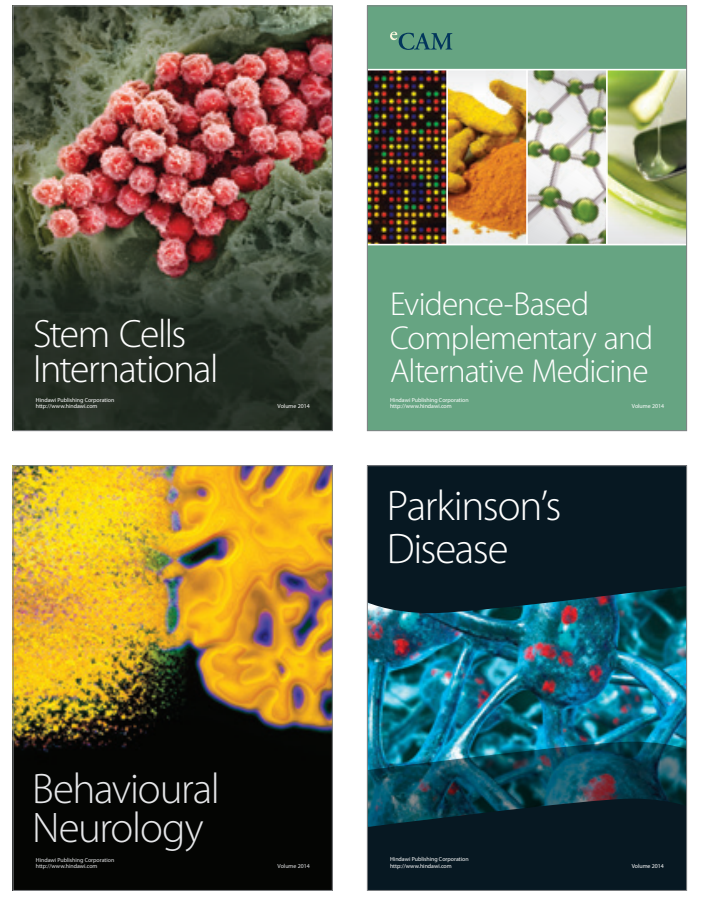
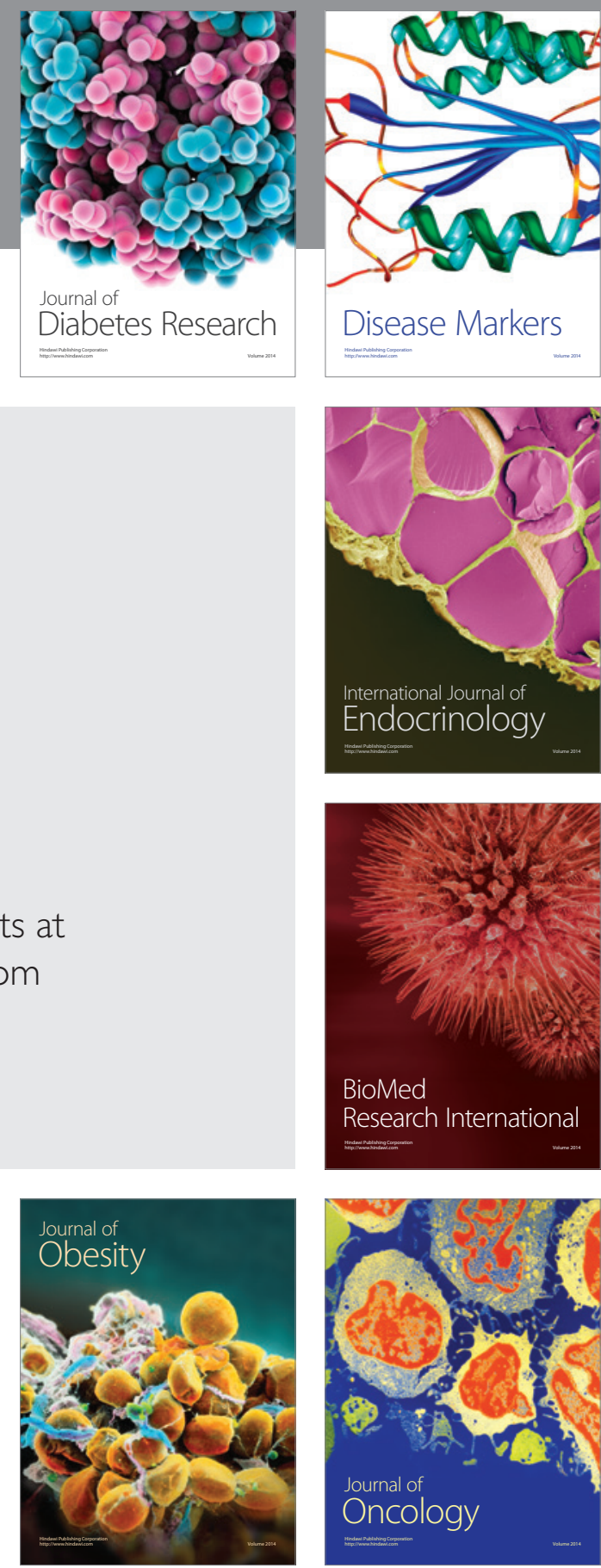

Disease Markers
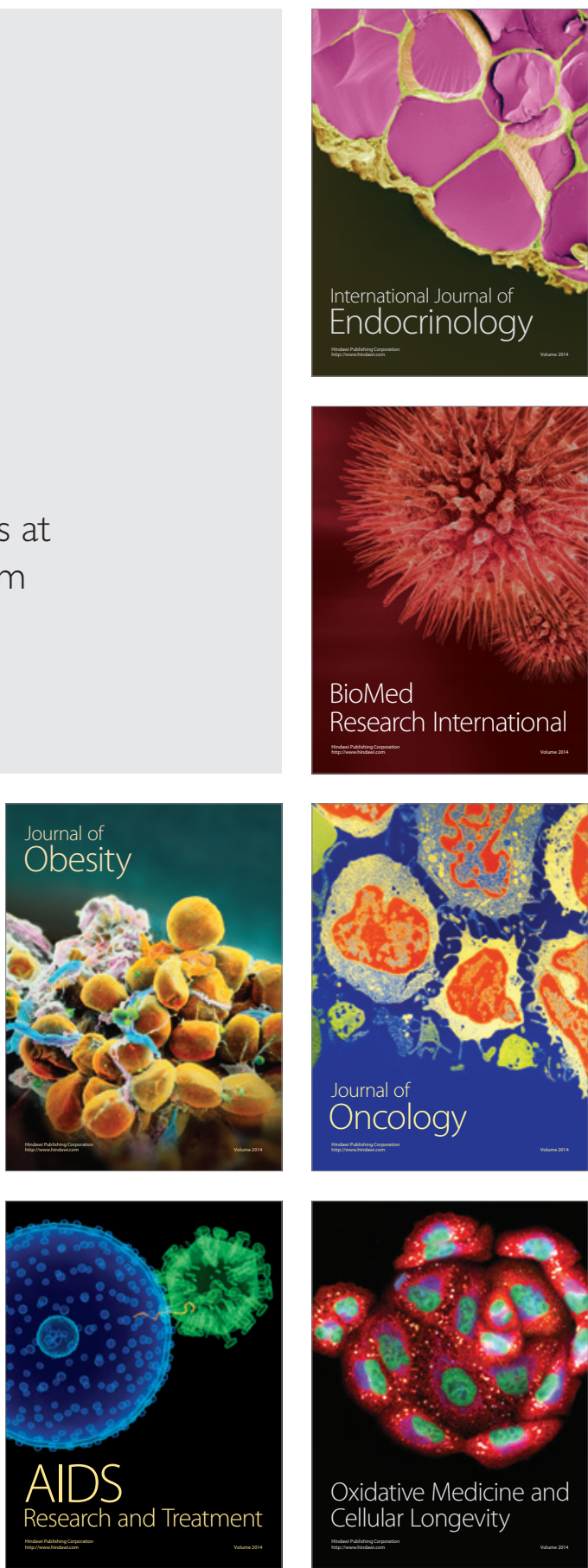